\section{Bibliografia}

Singer, Ausschießliche Patentlizenz- und Kowhow- Verträge nach deutschem, amerikanischem und europäischem Kartellrecht, 1997.

Hubmann. Götting, Gewerblicher Rechtsschutz, 1998.
Emmerich, Kartellrecht, 1999.

Reich, Europäisches Verbraucherschutzrecht: Binnenmarkt und Verbraucherinteresse, 1993.

Emmerich, Das Recht des unlauteren Wettbewerbs, 1998.

\title{
O Poder Judiciário e a Concretização das Cláusulas Gerais: Limites e Responsabilidade*
}

\author{
Ruy Rosado de eAguiax fuiniox \\ Ministro do Superior Tribunal de Justiça.
}

\section{1a Parte}

(1) bilidade".

ma que me foi proposto é: "O Poder Judiciário e a concretização das cláusulas gerais: limites e responsa-

Quero iniciar falando sobre o significado da concretização das cláusulas gerais dentro da atividade estatal.

Sabemos todos que a forma de atuação do Estado na economia tem sofrido variações que vão desde o absenteísmo do Estado mínimo ao Estado Intervencionista.

A partir da Revolução Francesa, observa-se acentuada tendência de intervenção na forma de direção, proteção ou de participação, variando as suas modalidades ou o seu ritmo conforme o país.

Embora se diga que na pós. modernidade o Estado deve estar cada vez mais ausente, a verdade é que ele dirige a economia.
Nos EEUU - símbolo do liberalismo - o agricultor planta aquilo que o Estado quer, não planta o que o Estado não quer; tem preço mínimo para o seu produto e re. cebe garantia de indenização pelo que não lhe foi permitido plantar.

Nos países neoliberais, a economia continua sendo presidida e orientada pelo Estado. Em um que nós conhecemos, essa direção se dá através de inúmeras medidas provisórias e resoluções de um ou de outro órgão governamental, além de atuação concreta no mercado financeiro.

Pois bem, na medida em que se faz presente o Estado no processo econômico, uma das áreas mais atingidas é o contrato.

O Prof. EROS GRAU acentuou que no regime ocidental capitalista em que vivemos, a sociedade está fundada em dois pilares: na idéia da propriedade privada dos bens de produção e na da liberdade de contratar, que é o seu corolário mais importan- 
te, pois é através do contrato que se dá a produção, a circulação e o consumo dos bens.

Essa liberdade de contratar decorre: a) em primeiro lugar, da titularidade da propriedade, tendo o proprietário o poder de dispor dos seus bens (autonomia privada); b) em segundo, do primado da autonomia da vontade (o homem retira de si o poder de querer, e porque é livre e racional, com seu querer e sua razão cria o próprio direito).

JOSSERAND observou que essa antiga teoria tradicional foi alterada reformulada pelo dirigismo contratual.

O contrato passou a ser visto não apenas como instrumento de regulação da vontade, meio de administrar interesses privados, exercício da autonomia privada, poder de dispor de seus interesses, mas também, como instrumento de ordenação da economia, um meio de realizar os fins do Estado. Menos serve para construir e realizar a vontade do indivíduo, mais para cons. truir e contribuir a que a sociedade possa atingir os seus fins econômicos, que são importantes, mas também para alcançar os fins éticos e sociais buscados pelo Estado, conforme o que está ordenado na Constituição.

Também sabemos todos que a liberdade contratual se expressa: a) pela decisão de celebrar ou não o contrato, e b) pela configuração interna que se quer dar à avença, com a escolha de suas cláusulas.

O Estado intervém nessas duas fases do contrato: alguns contratos são necessários e obrigatórios (como o seguro de auto- móveis por dano contra terceiros); outros são proibidos (a exemplo da exploração de bens ou lugares protegidos); algumas cláusulas são obrigatórias ou predeterminadas, como a relacionada com os juros ou com preços ou índices de correção; outras cláusulas são proibidas, como acontece com as abusivas condições gerais do negócio nos contratos de adesão ou com estipulação que expressa uma condição potestativa.

Disse-lhes isso para chegar à seguinte conclusão: o que observamos e constatamos facilmente, e tem sido continuamente repetido, é que a intervenção do Estado na Economia se dá pelo legislador, com a lei, e pelo governo (Executivo), com atos individuais ou normativos. Mas, além dessas duas, há ainda a intervenção do Estado pelo juiz, que se dá com a aplicação de cláusulas gerais no âmbito obrigacional, especialmente da cláusula geral da boa-fé.

Essa é a via que o Estado usa para modificar contratos, criar deveres anexos, limitar direitos, atribuir efeitos a condutas; e isso tanto para realizar os fins econômicos que são próprios dessas relações (como, por exemplo, para manter a leal concorrência), mas também e muito especialmente para realizar a justiça material do contrato.

Libertando-se do dogma da vontade, e acentuando a função social do contrato, instrumento socialmente útil, que vale se e enquanto for justo, o Estado que assume a decisão política de legislar através da técnica de introduzir cláusulas gerais em suas leis está consagrando a idéia de que as relações econômicas devem pautar-se por princípios éticos.
Encontro, portanto, dois enunciados:

- a cláusula geral é o meio através do qual o Estado atua pelo juiz na economia, permitindo-lhe conformar e configurar a relação contratual;

- o Estado que assim legisla assume o compromisso de submeter a economia a princípios éticos, pois as cláusulas gerais $\mathrm{da}$ boa-fé, da responsabilidade pelo dano, do enriquecimento ilícito, da lesão enorme, da função social do contrato, etc. irão permitir que a decisão sobre os negócios atenda a valores que não são econômicos, mas éticos, garantidores de uma justiça material.

Nesse ponto, devo olhar para a nossa realidade e a evolução mais recentè dos fatos.

O Brasil, que elaborou em 1850 , no gabinete de Mauá, o Código Comercial, e em 1917 o nosso Código Civil, não tinha essa preocupação, e as razões para isso são conhecidas e correspondiam ao pensamento político e filosófico então reinantes.

Foi na década de 70 , quando se redigiu o Projeto do Código Civil, que o desenho do nosso ordenamento civil passou a atender àqueles fins éticos a que antes me referi. Explicou o Prof. MIGUEL REALE que o Projeto estava iluminado pelo princípio da socialidade, sendo o seu exemplo mais significativo a norma que reconheceu no contrato a sua finalidade social. O Prof. MOREIRA ALVES lembrou que se tratava de cambiar a filosofia do nosso Direito Civil, e para isso foram introduzidas alterações pontuais, entre elas a do uso das cláu sulas gerais. O Prof. MIGUEL REALE ainda observou a mudança da fisionomia de algu- mas personagens que dominavam o Código Civil de CLÓVIS BEVILÁQUA: o proprietário, o marido, o testador e, muito especialmente, o contratante. Este deixou de ser o indivíduo singular, passando-se a considerar os contratantes, no plural, porquanto a relação é binária e existe em função da interação e da colaboração das duas partes.

O Projeto refere-se à boa-fé, à lesão enorme, ao enriquecimento injusto, ao abuso de direito, à onerosidade por fato superveniente, etc., conceitos que têm muito a ver com uma visão mais democrática e igualitária no direito das obrigações.

Isso evidencia que o Estado, refletido no Projeto, tinha o objetivo de exercer a intervenção na economia também na forma de proteção pelo juiz.

Depois do Projeto, sobreveio, em 1990, o Código de Defesa do Consumidor, com todos os princípios protetivos do hipossuficiente que conhecemos (equivalência da prestação, cláusulas abusivas, onerosidade, inversão do ônus da prova, desconsideração da pessoa jurídica, etc.).

Ocorre que esse momento, a meu juízo, passou. A tendência bem nítida é a de retorno ao predomínio da economia sobre o ético, de abandono da posição protetiva do Estado, deixando de garantir certas posições que, sem essa proteção, não subsistirão. Haverá com isso, certamente, uma perda de justiça, como já está havendo

Exemplifico lembrando, dentre muitos: 
- a legislação sobre planos e seguros de saúde veio dar menos garantias ao cidadão do que os tribunais já asseguravam;

- o fato de ter sido aprovada pelo Congresso Nacional - com a sanção presidencial, a lei que permite ao comércio do ensino a expulsão, da sala de aula, do aluno que não paga três prestações. Embora revogada, o fato é significativo;

- a falta de fiscalização, pelas agên cias governamentais, dos negócios que de veriam estar sujeitos ao controle do Estado, não sendo incomum a aprovação de cláusulas abusivas incluídas nos contratos de massa oferecidos ao público;

- os ambientalistas reclamam dos pra zos que estão sendo estendidos aos que ofendem a natureza;

- os previdenciários não se confor mam com a perda de participação nos órgãos diretivos, e assim por diante;

- há algum tempo, temos ouvido cadenciada referência aos males que decorrem dos juros altos, e a causa foi logo apontada: é a inadimplência que determina os juros anuais acima de $100 \%$ a.a., e por isso é preciso punir o devedor; em vez de reduzir os juros para diminuir a inadimplência, a solução foi logo encontrada: elaboração de uma norma que permite a capitalização dos juros, o que significa que eles duplicarão. Nesse entretempo, cogitase de garantir ao crédito bancário a prefe rência na falência, o que era até hoje do crédito trabalhista.

A mesma inclinação está acontecendo nos Tribunais, onde a aplicação dos princípios que significam um avanço na compreensão do contrato - amplamente aceitos e usados nos países mais avançados, especialmente depois da segunda guerra, há cinqüenta anos, portanto - encontra cada vez maior resistência, o que se nota muito nitidamente, por exemplo, na dificuldade de aceitação das regras e dos princípios do Código de Defesa do Consumidor, que substituiu a visão individualista da relação obrigacional para realçar o direito do cidadão de ser tratado em condições mínimas que lhe assegurem aquela justiça preconizada por Aristóteles, de ter um quinhão igual antes e depois do contrato. Recusada sistematicamente a aplicação dos seus princípios e reduzida a cada dia a sua área de incidência, em pouco tempo poderá ser lembrado apenas para algumas compras no supermercado.

Por isso, quero registrar que o Estado preocupado com a "socialidade", mencionada pelo Prof. MIGUEL REALE, desapareceu, e o ambiente político que propiciou a elaboração do Projeto, em 1975, e do CDC, em 1990, já não existe e, com isso, haverá cada vez maior resistência ao uso de cláusulas gerais em matéria negocial.

\section{$2^{\text {a Parte }}$}

O livro cujo lançamento hoje celebramos é o mais completo estudo que se fez no país sobre o tema das cláusulas gerais e, especificamente, a da boa-fé objetiva.

Para tratar do meu assunto, tive facilitado o trabalho: bastou-me lê-lo.

A autora da tese inicia sua abordagem das cláusulas gerais apontando a sua ligação com o problema das fontes, pois a cláusula é o meio que permite o ingresso, no ordenamento jurídico, de princípios valorativos, viabilizando a sua sistematização.

Mudando as fontes, muda o perfil do sistema, que passa de fechado para um sistema aberto, de auto-referência relativa. Deixa-se para trás o dogma da identidade do Direito-Lei, adequado ao sistema fechado, para um regime em que é preciso buscar, para cada caso, uma solução que lhe seja adequada, e para isso muitas vezes o operador não se satisfaz com o que está tipificado na lei.

Disse a autora: "Do ponto de vista de técnica legislativa, a cláusula geral constitui uma disposição normativa que utiliza, no seu enunciado, uma linguagem de tessitura intencionalmente 'aberta', fluida ou vaga, caracterizando-se pela ampla extensão do seu campo semântico, a qual é dirigida ao juiz de modo a conferir-lhe um mandato para que, à vista dos casos concretos, crie, complemente ou desenvolva normas jurídicas, mediante o reenvio para elementos cuja concretização pode estar fora do sistema". Como isso se dá por meio de uma exposição fundamentada, os elementos extra-sistemáticos são ressistematizados (p. 303).

A autora não aceita a oposição entre casuística (aquela que trabalha com tipos e faz a sua aplicação pela subsunção) e cláusula geral, como se tudo se resumisse a esses dois conceitos. O que se antepõe à casuística são as normas vagas, sendo uma dessas a cláusula geral, além dos princípios e dos conceitos indeterminados.
Há vagueza na norma quando se expressa de modo a permitir uma zona limite de incerteza, e isso se dá tanto com a cláusula geral como com os princípios e os conceitos indeterminados. Com isso, quer afirmar que há termos vagos que não são cláusulas gerais. Diante de termos indeterminados, basta ao juiz precisar o seu conteúdo para ter a norma pronta a ser aplicada, enquanto a cláusula geral exige um reenvio para outros fatores valorativos e um trabalho de criação.

Para distinguir a cláusula geral dos princípios, a autora entende que o cerne da definição de princípio está em que ele é uma norma considerada $\cdot$ como fundamento de outra. A cláusula geral pode expressar um princípio, mas não é um princípio. $O$ princípio pode ser expresso ou não, enquanto a cláusula geral sempre é e só pode ser expressa. Tanto assim que no nosso Direito, antes de termos a cláusula geral expressa na legislação civil, tínhamos o princípio não expresso da boa-fé, implicitamente admitido e decorrente do sistema. ALEXIS, em trabalho recente sobre o direito brasileiro, observou que antes da regulamentação dos dispositivos constitucionais que não são auto-aplicáveis, podem tais preceitos funcionar como princípios orientadores do sistema.

Já os termos indeterminados dos conceitos são apenas expressões cujo significado necessita de precisão.

A forma pela qual a cláusula geral se estrutura é que permite a atuação inovado. ra do juiz.

Disse a autora: "Diferentemente de outras normas, formadas através da técni- 
ca da casuística, cujo critério de valoração já vem indicado com relativa nitidez - sendo desenvolvido por via dos vários métodos de interpretação - , a cláusula geral introduz no âmbito normativo no qual se insere um critério ulterior de relevância jurídica, à vista do qual o juiz seleciona certos fatos ou comportamentos para confrontá-los com um determinado parâmetro e buscar, neste confronto, certas conseqüências jurídicas, que não estão prédeterminadas. Daí uma distinção fundamental: as normas cujo grau de vagueza é mínimo implicam seja dado ao juiz tão-somente o poder de estabelecer o significado do enunciado normativo; já no que respeita às normas formuladas através de cláusula geral, compete ao juiz um poder extraordinariamente mais amplo, pois não estará tão-somente estabelecendo o significado do enunciado normativo, mas por igual, criando direito, ao completar a fattispecie e ao determinar ou graduar as conseqüências". (p. 330)

A cláusula geral, portanto, exige do juiz uma atuação especial, e através dela é que se atribui uma mobilidade ao sistema, mobilidade que será externa, na medida em que se utiliza de conceitos além do sistema, e interna, quando desloca regramentos criados especificamente para um caso e os traslada para outras situações. Foi assim, no primeiro caso, que o Tribunal reconheceu a obrigação alimentar do concubino em favor da companheira, dez anos antes de lei reconhecendo a existência dessa relação e atribuindo-lhe tal efeito. No segundo, quando deslocou a regra do art. 924 do CC, criada para reduzir a cláusula penal convencionada pelas partes para, com a mesma norma, limitar quantitativos de multas previstas em lei.

Sendo a cláusula geral uma norma que permite a solução do caso, é apropriada para a sua aplicação a tópica, que é "técnica de pensamento orientado por problemas", e serve para resolver a seguinte questão: o que, aqui e agora, é o justo.

Tratando sobre a boa-fé objetiva no sistema contratual brasileiro, o Prof. MOREIRA ALVES, nosso mais ilustre civilista, cita a lição da Prof JUDITH MARTINS COSTA, quando faz a distinção entre a cláusula geral e o conceito indeterminado, dando como exemplos os arts. $4^{\circ}$, III, e $51, I V$, do CDC, o primeiro sendo uma cláusula geral, e, o segundo, um conceito indeterminado. A técnica da cláusula geral, refere o il. Professor, propiciará atuação judicial mais criadora; embora não arbitrária.

\section{$3^{a}$ Parte}

E com isso chego à parte final do meu trabalho, tratando dos limites e da responsabilidade da atividade do juiz na aplicação das cláusulas gerais.

Tenho para mim que cláusula geral é a norma que deixa em aberto a descrição da conduta devida. Assim acontece, por exemplo, com o tipo penal aberto do art. $121, \S 3^{\circ}$, do Código Penal: causar a morte de alguém por culpa. Sabendo-se que a culpa consiste no descuido, na violação a um dever de cuidado, a norma positivada não descreve que cuidado deveria ser observado na situação concreta. A lei remete ao juiz a elaboração da norma de dever para o caso, e do confronto dessa norma - que é judicial, criada concretamente para aquela hipótese - com a conduta efetivamente adotada pelo agente é que se saberá se o comportamento foi lícito ou ilícito.

Assim também acontece quando a norma determinar ao contratante comportar-se de acordo com a boa-fé, mas não lhe diz qual o comportamento esperado nas circunstâncias do negócio. Havendo o litígio, fixará o juiz o comportamento que deveria ter sido observado quanto ao prazo, modo, lugar, quantidade, qualidade da prestação, etc.

Evidentemente que isso gera insegurança, pois o contratante não sabe o que o juiz entenderá como sendo o comportamento devido; a descrição dessa conduta não está na lei.

Disso sobressai a responsabilidade do juiz de agir com extremo cuidado ao estabelecer tal norma de dever, que ele usará como parâmetro para resolver o caso. Deverá ter atenção para os valores da comunidade, saber quais as condutas normalmente adotadas naquele lugar e naquelas circunstâncias e verificar de que modo poderia a parte cumprir com tais expectativas.

Nesse trabalho criador, o juiz deve, mais do que em outras ocasiões, fundamentar as suas decisões, porque ele deve explicar às partes e à comunidade jurídica como e por que tais condutas foram consideradas as devidas na situação do processo, pois foi nessa norma de dever (criada por ele para o caso) que alicerçou a solução da causa.

É um trabalho bem mais complexo do que o da simples subsunção. Nesta, o juiz já tem a norma; definido o fato e escolhida uma das normas positivas aplicáveis, basta explicar as razões dessas duas proposições para que se entenda a conclusão. No caso da cláusula geral, contudo, primeiro se exige a definição da própria norma de conduta, cujo conteúdo tem de ser encontrado para o caso, e somente depois disso será feita a subsunção da conduta efetivada em relação a tal preceito.

A sua fundamentação é exposta às partes e ao sistema judiciário, por onde tramitará o processo, com possibilidade de sucessivos recursos e juízos de revisão. É um modo de controlar.

Além disso; a comunidade jurídica tem hoje, e cada vez mais, conhecimento e informação do que está sendo julgado pelos tribunais (a página do STJ na Internet é consultada 200 mil vezes por dia), e a opinião da academia, das universidades, das entidades que se organizam em defesa de interesses setoriais, tudo serve para impedir que se repitam decisões arbitrárias e fora do contexto social.

Os limites do trabalho de criação não estão no sistema legislado, pois o operador poderá ter de recorrer a dados e elementos metajurídicos. No entanto, no Brasil, com a Constituição de 1988, com tantos enunciados orientadores de direitos e de valo. res, dificilmente uma situação proposta em juízo não será resolvida a contento, seguindo os princípios constitucionais a que remete a cláusula geral.

É de natureza social a responsabilidade do juiz que emprega mal os poderes que lhe concede a cláusula geral, ou que não a usa nos casos em que deveria fazê-lo. 
Isto é, não é caso de responsabilidade jurídica, pela qual o juiz que pratica certa conduta sofre sanção prevista em lei. Trata-se aqui de uma atuação no âmbito estrito do exercício da jurisdição, e nosso sistema não conhece nenhuma hipótese de responsabilidade do juiz em caso tal. Há, é certo, previsão de responsabilidade jurídica em alguns casos, como, por exemplo, quando o Código Civil trata dos interesses dos incapazes e do descuido com o seu patrimônio, ou quando o Código de Processo Civil prevê responsabilidade do juiz por falta de oportuna manifestação. Mas esses são isolados e de escassa ou nenhuma aplicação. Também a responsabilidade funcional é apurada diante de faltas outras que não no desempenho da liberdade de julgar. A responsabilidade política, de sua vez, está prevista apenas para os Ministros do Supremo Tribunal Federal. Por fim, a responsabilidade civil do Estado pelos atos dos juízes tem recebido sempre interpretação restritiva. Mas essas situações todas prevêem aplicação de uma sanção prevista em lei, por isso digo que são de responsabilidade jurídica.

Não havendo sanção jurídica prevista em lei, aplicável ao juiz que deixa de fazer o devido uso da cláusula geral, estamos diante de um caso de responsabilidade social. Nesta, a relação se estabelece diretamente entre o juiz e a sociedade, que se manifestará através dos diversos modos e meios de controle difuso. Para isso, é preciso em primeiro lugar garantir a publicidade e a divulgação das decisões; em segundo, contar com uma sociedade organizada, da área técnica ou não, que tenha condições de avaliar a decisão e dar a resposta. Nesse particular, exercem importante papel a imprensa, os meios eletrônicos de comunicação, os livros especializados e os periódicos, que divulgam, analisam e criticam as decisões.

$\mathrm{Na}$ verdade, a primeira e principal responsabilidade é a pessoal, pela qual o juiz é chamado a prestar contas perante sua própria consciência.

Em resumo, a cláusula geral impõe ao julgador o uso de uma técnica judicial especial de julgar, estando o seu exercício limitado pelo ordenamento constitucional; o desempenho arbitrário ou omisso gera a responsabilidade social do juiz.

Quero terminar dizendo da honra que tenho em estar aqui para testemunhar a qualidade do trabalho profissional desenvolvido pela Prof ${ }^{a}$ JUDITH MARTINS COSTA, que enobrece esta Casa, engrandece o Curso de Mestrado e Doutorado a que pertence e que prossegue com o mesmo brilho a tradição dos Martins Costa.

A tese que escreveu para o seu doutoramento, hoje transformada em livro, teria sido motivo de especial satisfação do Prof. CLÓVIS DO COUTO E SILVA, a quem tanto devemos, pelas lições e pelo exemplo de sempre procurar a excelência acadêmica, o que a Dra. JUDITH alcançou, inteligência privilegiada a serviço do Direito.

\title{
Nuevo Dinamismo o Estancamento: El futuro de las relaciones entre el Mercosur y la UE*
}

\author{
Wrich Wehnex
}

Profesor Visitante DAAD/CAPES en la Facultad de Derecho de la Universidad Federal de Rio Grande do Sul; Doctor en Derecho por la Universidad de Colonia, Alemania.

\section{Introducción}

W $n$ el transcurso del año pàsado tuvieron lugar acontecimientos importantes para las relaciones entre la Unión Europea ${ }^{1}$ y el Mercosur. Cabe destacar entre ellos el encuentro de los jefes de Estado y de Gobierno de la UE, del Mercosur y de Chile en el marco de la Cumbre de Rio en junio de 1999. También tiene importancia la entrada en vigor del Acuerdo Marco Interregional poco después de la cumbre, el 1 de junio del mismo año.

Ahora ya no son exclusivamente los juristas ibéricos que acompañan el desarollo dentro del Mercosur. En el resto de los paises europeos los autores muestran su interés en los esfuerzos de integración en el Cono Sur². El interes europeo se debe por un lado a los

- Este trabajo no habría sido posible sin la más valiosa ayuda de la Doctora Marta Jiménez Olivar, Profesora de Derecho Internacional Público en las Universidades UFRGS y PUC en Porto Alegre. Portanto quiero agradecerle una vez más por la colaboración productiva y agradable. El presente trabajo está basado en el artículo „EU und Mercosur: Auf dem Weg zur Freihandelszone?" del mismo autor, publicado en la revista „Recht der Internationalen Wirtschaft", № 5/2000, pág. 370 ss.

1. El término „Unión Europea (UE)" se usa aqui para hacer referencia genérica al conjunto de los 12 Estados que firmaron el Tratado de Maastricht y a los 3 Estados que se adhirieron a este Tratado en el momento de transformarse en miembros de la UE- debe tenerse en cuenta que la UE queda configurada por las tres Comunidades Europeas y otras áreas de cooperación intergubernamental ver al respecto art A pár 3 del Trotado de la Unión Europea (los articulos A a E del Tratado de la Unión Europea han sido sustituidos por los artículos 1 UE a 28 UE).

2. Ver de la doctrina alemana: Renata Martins, MERCOSUR: Der Südamerikanische Gemeinsame Markt im Überblick, en: Recht der Internationalen Wirtschaft 1999, pág. 851 ss.; Jürgen Samtleben, Das internationale Prozeß- und Privatrecht des Mercosur, Rabels Zeitschrít, tomo 63 (1999), pág. 1 ss.; observando el proceso continuamente: Calixto Salomão Filho /Jürgen Samtleben, Der Südamerikanische Gemeinsame Markt - Eine rechtliche Analyse des Mercosur, en: Wertpapier Mitteilungen 1992, pág. 1345 ss., pág. 1385 ss.; Samtleben, Jürgen, Der Südamerikanische Gemeinsame Markt (Mercosur) und seine neue Verfassung, en: Wertpapier Mitteilungen 1996, pág. 1997 ss.; ibíd, Das Recht des Mercosur - wichtig für Europa?, en: Europäische Zeitschritt für Wirtschaftsrecht 1998, antes de pág. 65; ibíd., Las Perspectivas para un Tribunal de Mercosur y la Experiencia Europea, en: Jurisprudencia Argentina, 1998 tomo l, pág. 786 ss.; de otros paises: Wrobel, $P_{\text {, }}$ Mercosur Atter the Brazilian Financial Turmoil, en: International Spectator 1999, Vol. 34, № 3, pág. 81 ss.; Page, S., The Relationship between the European Union and Mercosur en:International Spectator1999, Vol. 34, № 3, pág. 91 s.; Mercosur, engouement malgre les turbulences, en: Moniteur du Commerce International (MOCl) 1999, № 1377, pág. 55 ss. 